\title{
Slow the Spread of COVID-19-and Get your Audiology CEUs at the Same Time
}

\author{
Erin Piker ${ }^{1}$ Gary P. Jacobson ${ }^{2}$ Devin L. McCaslin ${ }^{3}$ \\ 1 Department of Communication Sciences and Disorders, James \\ Madison University, Harrisonburg, Virginia \\ 2 Department of Hearing and Speech Sciences, Vanderbilt University \\ Medical Center, Nashville, Tennessee \\ ${ }^{3}$ Department of Audiology, Mayo Clinic, Rochester, Minnesota \\ ${ }^{4}$ Managing Editor, American Academy of Audiology, \\ Reston, Virginia
}

J Am Acad Audiol 2020;31:469-470.

In light of the outbreak of the respiratory disease now referred to as COVID-19, our nation has learned about what the terms "flattening the curve" and "social distancing" mean.

There is no question that, since January, those of us working in the health care industry have had to make some tough decisions and reinvent our practices in response to this pathogen. This is because the infection spreads by coughing, sneezing, or coming in contact with a surface that has the virus on it and then touching the eyes or mouth. The handshake is to be avoided, teleworking has become the new normal, and we are trying to educate our children at home while at the same time doing conference calls.

In order to stop the spread of this infection, healthy people need to avoid being exposed to infected people. Experts are recommending that we not leave our homes, "shelter in place," and avoid large gatherings. Of course, our professional meetings fall into the category of large gatherings and, in addition to not being able to catch up with friends and classmates, we are also unable to attend lectures, learn, and obtain our required continuing education units (CEUs).

Although there are many online opportunities to obtain your CEUs, there is one path that is readily available to members of the American Academy of Audiology that can be taken from anywhere. The Academy's eAudiology program incorporates several ways to earn CEUs online, including the JAAA CEU program.

\section{The JAAA Online CEU Program}

The JAAA online CEU program is self-paced and is focused on an article chosen from at least 8 of the 10 JAAA issues published each calendar year. To earn $0.2 \mathrm{CEU}$ credits per issue, participants read the selected article and complete a 10 -question multiple-choice online exam. The exam is grad-
Kathie Felix 4

ed instantly, feedback is provided on correct answers, and the CEUs are automatically reported to the Academy.

Participants may choose to complete their CEUs for each article individually (i.e., as $J A A A$ issues are published) or may choose to complete all of the CEUs at one time near the end of the year. With at least 8 issues of JAAA per year, participants can earn up to 1.6 CEUs annually. Information about the program can

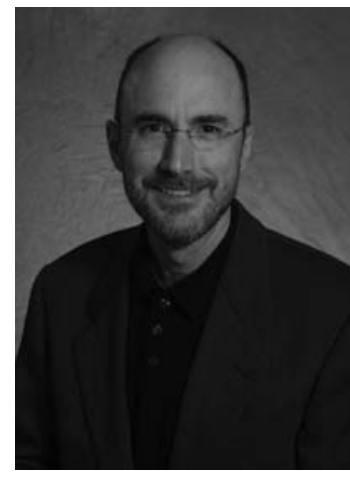

Gary P. Jacobson



Devin L. McCaslin be found at https://www.audiology. org/professional-development/eaudiology/jaaa-ceuprogram.

Although we choose the CEU article for every issue, the exam questions are written by the article's author. That means the researcher who designed the study and authored the manuscript develops the learner outcomes and tells us the relevant take-home points they want the reader to learn. The exam questions are not meant to be tricky; they are meant to emphasize the key points from each article.

One of the best things about the JAAA online CEU program is that each CEU opportunity focuses on a different audiology topic. Participants can stay up to date on current research trends and findings in all areas of audiology. This is especially helpful if you have sub-specialized and tend to get all your CEUs in a single topic area.

The JAAA online CEU program encourages clinicians to read at least one audiology research article eight times each year that may be outside of their area of expertise. As someone who has chosen a science subfield within audiology, I find this aspect to be a refreshing change of pace from my usual scholarly readings.

Copyright $\odot 2020$ by the American

Academy of Audiology. All rights reserved. Thieme Medical Publishers, Inc., 333 Seventh Avenue, New York, NY 10001, USA.

Tel: +1(212) 760-0888.
DOI https://doi.org/ 10.1055/s-0040-1715813. ISSN 1050-0545. 


\section{Become a JAAA Peer Reviewer and Earn CEU Credits}

In addition to the JAAA CEU program, it is possible to earn CEUs by participating as a peer reviewer for the journal. To become a peer reviewer, you may either be invited by one of the editors or you may contact the editors through the journal email address (jaaa@audiology.org) and request to be considered as a peer reviewer. The editors will ask for your $\mathrm{CV}$ and references from two sources who can attest to your abilities as a reviewer.

If you have submitted manuscripts to be considered for publication and they have not fared well, it may be because you have not had the opportunity to view the peer-review process from the perspective of the reviewer. It is important for the reviewer to identify the virtues of each paper. However, it is also the reviewer's responsibility to identify the shortcomings of each manuscript and to suggest to the editors whether the paper can be revised (a summary decision of "accept as is" or "accept with minor revision" or even "accept following major revision") or not (i.e., a summary decision of "reject" or "major revision and rereview").

We ask reviewers to use a structured format when they complete their reviews. We suggest that, for the first two or three reviews, you find a mentor who has had success publishing in medical journals. For your expertise, the journal and the Academy will provide you with 0.1 CEUs. If you review five manuscripts during a calendar year, you will earn 0.5 CEUs (on average, you must accumulate 1.0 CEUs per year to maintain your CCC-A).

Information about the review process can be found at https://www.audiology.org/publications-resources/journalamerican-academy-audiology/instructions-reviewers.

\section{Earn as Many As 2.1 CEUs}

Between both the JAAA online CEU program and the JAAA peer reviewer opportunity, Academy members have the potential to earn up to 2.1 CEUs annually without leaving the comfort of their home. And, in these current times, you can both slow the spread of COVID-19 and get your audiology CEUs at the same time. 